\title{
Analysis of the Response of a One-Storey One-Bay Steel Frame to Blast
}

\author{
Rupert G. Williams, ${ }^{1}$ William A. Wilson, ${ }^{1}$ and Reisa Dookeeram ${ }^{2}$ \\ ${ }^{1}$ Department of Civil and Environmental Engineering, Faculty of Engineering, The University of the West Indies, \\ St. Augustine Campus, St. Augustine, Trinidad and Tobago \\ ${ }^{2}$ Atlantic Project Consultants Limited, Valsayn, Trinidad and Tobago \\ Correspondence should be addressed to Rupert G. Williams; rupert.williams@sta.uwi.edu
}

Received 24 February 2016; Accepted 5 May 2016

Academic Editor: Lucio Nobile

Copyright (c) 2016 Rupert G. Williams et al. This is an open access article distributed under the Creative Commons Attribution License, which permits unrestricted use, distribution, and reproduction in any medium, provided the original work is properly cited.

In recent years, there has been a considerable increase in perceived risks of blast loading attacks or similar incidents on structures. Blast design is therefore a necessary aspect of the design for building structures globally and as such building design must adapt accordingly. Presented herein is an attempt to determine the numerical response of a seismically designed single-degree-of-freedom (SDOF) structure to blast loading. The SDOF model in the form of a portal frame was designed to withstand a typical seismic occurrence in Northern Trinidad. Blast loads caused by applying a $500 \mathrm{~kg}$ charge weight of TNT at standoff distances of $45 \mathrm{~m}, 33 \mathrm{~m}$, and $20 \mathrm{~m}$ were then applied to the model. The blast loading on the frame was determined using empirical methods. The analytical study showed that the seismically designed SDOF plane frame model entered the plastic region during the application of the blast load occurring up to the critical standoff distance.

\section{Introduction}

Previous to the 1960s, the design of structures based upon results of catastrophic events was reserved for facilities where accidental or chemical explosions could occur. Blast design criteria and methods had just started to emerge in the late 1960s and initially as such did not include a detailed or reliable quantitative basis for assessing the structural implications of a structure subject to blast loads [1]. Catastrophic events such as the explosion that demolished the Alfred P. Murrah Federal Building in Oklahoma City in 1995 and the September 11, 2001, attacks in New York City and Washington triggered a widespread sense of unease concerning the vulnerability of buildings, bridges, tunnels, and utilities. In recent years, terrorism has been an unfortunate reality and structural design for uncommon loads is critical. Blast design methods, acceptance criteria, and methods of analysis, for the most part, are classified for national security reasons and as such are not readily available to civilians [2].

An explosion is a rapid release of energy in the form of light, heat, sound, and shock wave. A shock wave, or compression wave, results from the rapid expansion of hot gas from the detonation of an explosive charge, which propagates through the air [3]. As the shock wave expands, pressures reduce rapidly with distance. When it meets a surface in the line-of-sight of the explosions, it is reflected and amplified by a factor of up to thirteen [4]. Conventional structures are vulnerable to damage from blasts because, in most situations, the magnitudes of the design loads are lower than those produced by an explosion at critical standoff distances.

\section{Blast Load Phenomenon}

When an explosive is detonated, an immense amount of energy is released causing the surrounding air to compress as the explosive gas expands [5]. This compressed air is called the blast wave which travels away from the blast source therefore decreasing the pressure amplitude, while the blast duration increases [6]. This phenomenon is illustrated in Figure 1.

Initially, the blast wave increases to a pressure value above the ambient atmospheric pressure, known as the peak overpressure. This overpressure decays as the shock wave expands away from the source of the explosion. The wave 


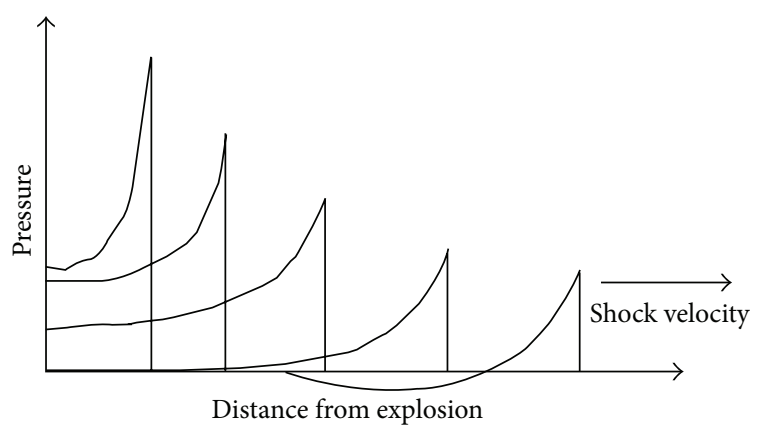

Figure 1: Blast wave propagation [7].

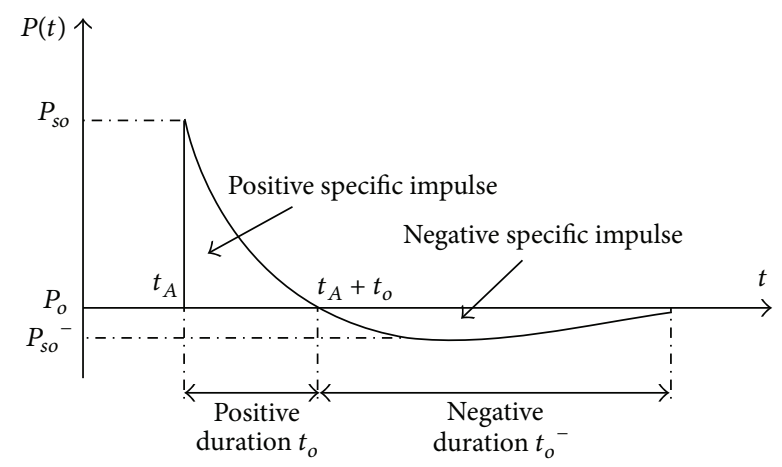

FIGURE 2: Blast wave pressure-time history [7].

takes the time, $t_{A}$, to reach its peak overpressure; however the time period is very small and is therefore usually assumed to be negligible and equal to zero for design purposes [11]. The shock wave travels with a velocity, $U$, and a peak pressure, $P_{s o}$. After the wave reaches its peak overpressure value, the pressure exponentially decreases. This is called the positive phase of the blast [12], where the time taken for the pressure to fall from the peak overpressure to ambient pressure is $t_{o}$. When the blast pressure reaches ambient pressure, it continues to drop even further, to below the ambient pressure; this is called the negative phase of the blast, which lasts for a longer period than the positive phase. This time period is denoted as $t_{o}{ }^{-}$ and the minimum pressure value as $P_{s o}{ }^{-}$. During this negative phase, a suction force is experienced by the structures subject to the blast. This explains why, following an external blast explosion experienced by a structure, the structure's glass and facades are found along the structure's exterior rather than propelled into the structure itself [11]. For structural designs, however, the negative phase of the explosion is usually not taken into consideration. The simplified forcing function is shown in Figure 2.

Figures 3(a) and 3(b) show the complex nature involving blast wave and building interaction. It shows that the initial wave from the blast strikes the building causing the building to be loaded by both overpressure and drag forces with the formation of complex vortices.

The parameters of a blast depend on the amount of energy released by the detonation and the standoff distance from the explosion [11]. See Figure 4.
TABLE 1: Conversion factors for typical explosives.

\begin{tabular}{lcc}
\hline Explosive & $\begin{array}{c}\text { Mass specific energy } Q_{\text {Exp }} \\
(\mathrm{J} / \mathrm{kg})\end{array}$ & $\begin{array}{c}\text { TNT equivalent } \\
\left(Q_{\mathrm{Exp}} / Q_{\mathrm{TNT}}\right)\end{array}$ \\
\hline Composition B & 5.19 & 1.15 \\
HMX & 5.68 & 1.26 \\
Nitroglycerin & 6.70 & 1.48 \\
Nitrocellulose & 4.52 & 1.00 \\
RDX & 5.36 & 1.185 \\
TNT & 6.70 & 1.00 \\
ANFO & & 0.82
\end{tabular}

Universally, blast effects are given a scaling distance relative to $\left(E / P_{o}\right)^{1 / 3}$, where $E$ is the energy released by the blast in $\mathrm{kJ}$ and $P_{o}$ is atmospheric pressure (which is typically $100 \mathrm{kN} / \mathrm{m}^{2}$ ); this relationship is known as the mass specific energy. In general practice however, charge weight, $W$ (the basic explosive input), is expressed as an equivalent mass of TNT. Refer to Table 1.

The most common form of scaling the blast wave (Hopkinson-Cranz and Sachs, cited in [13]) uses an equation which is formulated using two blast loads which are situated at the same scaled distance away from the target, having similar geometry and with the same atmospheric pressure, however with different charge weights, $W$. This arrangement produces similar blast waves [11]. The scaled distance parameter, $Z$, is therefore used to determine the "equivalent" design pressure impulse. There are also published curves based on these theories [14]. The charge weight, $W$, and standoff distance, $R$, are therefore two necessary inputs for the scaled distance parameter, $Z$.

\section{Previous Research}

A review of the methods for predicting bomb blast effects on buildings [15], following the bombing of the World Trade Center in New York City in February of 1993, when a truck bomb was detonated below the North Tower, and the devastating attack against the Alfred P. Murrah Federal Building in Oklahoma City in April 1995 and of course the recent collapse of the World Trade Center Towers, indicates the vulnerability of civilian buildings as terrorists targets. It is therefore a necessity to incorporate blast loading effects into the design of building structures.

The US Department of the Army Corps, in the 1960s, released a technical manual entitled Structures to Resist the Effects of Accidental Explosions, which was the first manual released that involved the analysis of blast loading on structural elements and structures as a whole. In 1990, a revised edition of the manual was released. The procedure commonly followed in the practice of blast design is the determination of the threat, development of the design loads for the determined threat, analysis of the behavior of the structure and the selection of the structural systems, the design of structural components, and the retrofitting of existing structures [15]. 


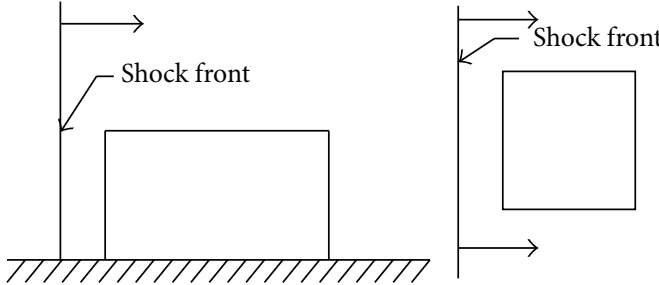

(A) Shock front approaches structure

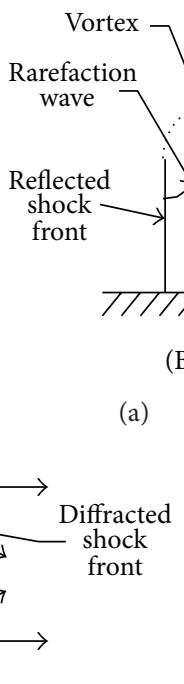

(a)

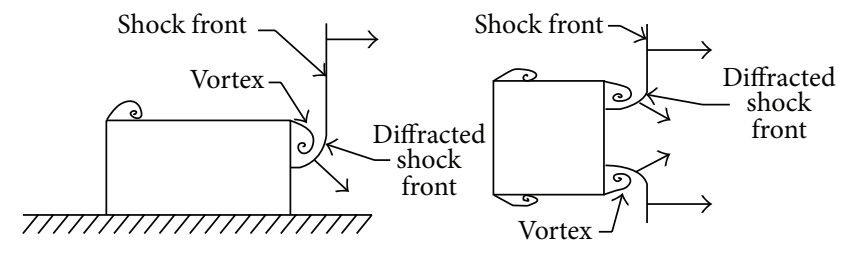

(C) Diffraction continues across rear surface
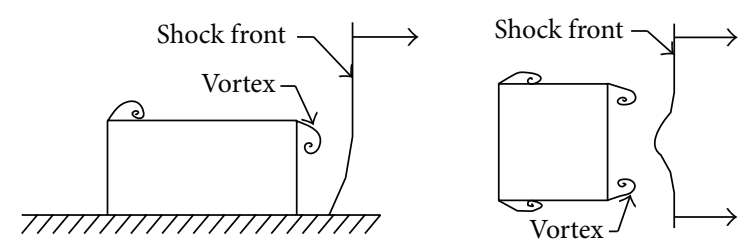

(D) Diffraction is complete. Shock front passes beyond structure

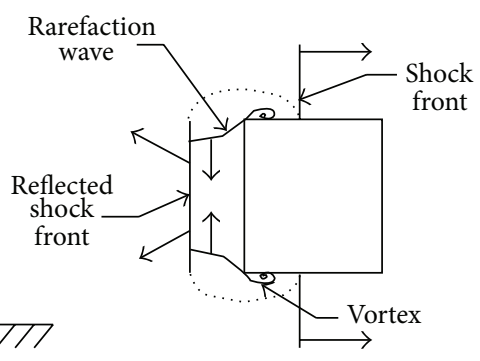

Shock reflected from front surface and diffracts over structure

(b)

Figure 3: (a) Schematic of blast wave interaction with a building ((A) and (B)) [8]. (b) Schematic of blast wave interaction with a building $((\mathrm{C})$ and $(\mathrm{D}))$ [8].

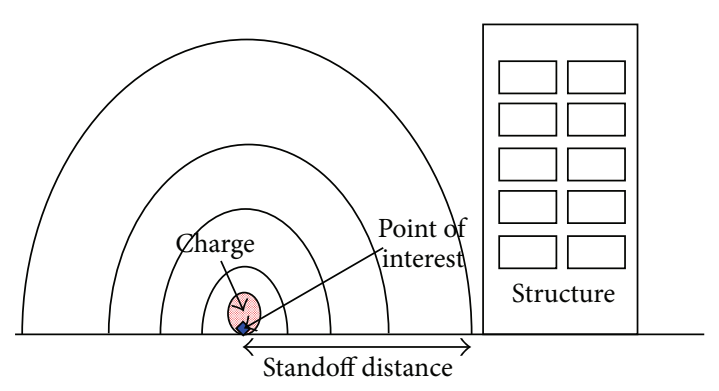

FIGURE 4: Surface blast environment; standoff distance.

According to Remennikov (ibid.), the following methods are available for prediction of blast loading response on building structures:

(i) Empirical methods.

(ii) Semiempirical methods.

(iii) Analytical (or first-principle) methods.

(iv) Numerical methods.

The empirical and semiempirical methods refer to graphs and charts which are essentially correlations with data acquired through previously conducted experiments. There are limitations however with this approach since the data is constrained by the extent of the core experimental archive. Also the accuracy of all empirical equations diminishes as the explosive event becomes increasingly near field [16]. Unlike the empirical methods which focus on past experimental data, analytical (also called first-principle) methods are based purely on mathematical equations. These equations describe the basic laws of physics, whereby the principles include conservation of mass, momentum, and energy. Numerical models are commonly termed computational fluid dynamics (CFD) models [15] and make use of discrete particle theories.

Following the four major bombings which took place within Mainland United Kingdom (UK) within the last ten years, the 1992 St. Mary Axe, the 1993 Bishopsgate, and the 1996 Docklands and Manchester bombings, many property owners have realized the threat of terrorists attacks. As such, Philip Esper in 2003 investigated the damage caused by these attacks and the refurbishment of numerous commercial buildings throughout the UK. Esper was able to adopt numerical modelling, as well as laboratory and on-site testing for the investigation of the damage, and therefore assessed the dynamic response of the affected buildings. It was concluded that the ductility and natural period of vibration of a structure govern its response to an explosion. From the analysis it was also concluded that, given the unpredictability of blasts effects and the fact that on-site and laboratory testing of structural elements were more costly and time-consuming, finite element analysis is a more adaptable and economic approach. In addition, ductile elements, such as steel and reinforced concrete, can absorb significant amount of strain energy, whereas brittle elements, such as timber, masonry, and monolithic glass, fail abruptly [17].

Ultra High Performance Concrete (UHPC) is widely used in modern structures due to its large potential to resist extreme loading conditions, such as impact or explosions [18]. However from experiments conducted on the behavior of such material during explosions, the three major modes of damage were observed, that is, flexural, shear, and spalling [19]. In addition, finite element modelling has been carried out on other systems, including tuff stone masonry [20]. This study focused on the blast resistance of the material. 
Goyal [21] conducted a study in order to quantify blast loading as a high pressure, short-duration shock load over an entire building and also on each of a building's individual structural members. Numerical analysis was performed in order to predict the blast induced pressure exerted on the building and structural members and their respective responses. The response of the structure was also studied. The study concluded that although considerable effort and skill were required to perform the numerical analysis, one of the most critical aspects of the investigation defined the parameters of the blast wave itself, especially since these blasts are highly unpredictable in most circumstances. Also, the desired response limitations of the building must be defined, in terms of rotations and ductility factors, for example. The study showed that results from a developed system can be meaningless due to the limitations of the model and the aforementioned uncertainties involved in the investigation of blast loading. It was concluded that these developed systems should be tested in the field and the data collected should be used to improve the design and develop the mathematical model [21].

Remennikov [15] studied the current methods utilized in the prediction of building responses to bomb blasts when a building is subjected to a detonation without the interference effects of neighboring buildings. An empirical approach was adopted to determine the blast pressures. Simplified analytical techniques (such as SDOF numerical models) were then described in order to obtain relatively conservative estimations of responses of the blast effects. This included the use of design curves presented in the US Department of the Army 1990 Manual, where the blast wave parameters were presented in terms of scaled distances for free air burst, air burst, and surface burst environments, on the latter of which this study will be focused. The paper also presented analytical and numerical techniques currently available to effectively determine the loading on structures due to blasts. Blast effects of an explosion of $100 \mathrm{~kg}$ TNT located 15 meters away from a single office block were investigated. The simplified empirical approach showed results of a $30 \%$ higher overpressure, a $25 \%$ higher positive phase duration, and between 2 and $10 \%$ higher reflected impulse than the numerical methods. Remennikov (ibid.) showed that the simplified technique can be used to compute conservative values for a building's response to a blast. For more accurate predictions, a MDOF (multi-degreeof-freedom) numerical model is to be used.

Ngo et al. [7] studied blast loading and blast effects on structures by the use of various methods. An overview on the design and analysis of buildings subjected to blast loads and structural responses are described. The study explained that the prediction of the blast pressures and their effects on buildings as a whole and its individual element responses involved nonlinear behavior; it was suggested that any computational method used must therefore be validated by relating calculations to experimental data. The paper described that although computational methods are less conservative than empirical methods, they required considerable skill to evaluate the code outputs and as such may skew the appropriateness and correctness of the modelled situation rendering the results meaningless. Case studies involving the analysis of reinforced concrete (RC) columns, RC slabs, and exterior building facades are described whereby technical design manuals based on the empirical design methods were implemented. The study now assists engineers in determining of the appropriate design considerations to implement against extreme events such as high velocity impacts [7]. Moon [22] investigated the dynamic properties of a RC column, such as the reinforcing steel and the concrete properties, under high strains experienced by the structure as a result of blast loads. One of the aims of the study was to calculate the blast loads on a structure given the basic blast properties such as charge mass and standoff distance. These calculations were based on existing graphs and charts; however, once the loads were computed, a finite element model was used to determine the responses of the column.

The prediction of blast loading, by either empirical, semiempirical, or numerical analysis, can be carried out as described above; damage, however, may be evaluated by explosive testing, engineering analysis, or both. Often, destructive testing is a rather expensive option for the general design of buildings, and therefore engineering analysis is preferred. Explosive testing, however, is actively conducted by federal government agencies such as the Defense Threat Reduction Agency, Department of State, and US General Services Administration. In order to accurately represent the response of an explosive event, testing must be conducted, or in terms of engineering analysis, the analysis needs to be time dependent and account for nonlinear behavior [23]. Nonlinear dynamic analysis techniques are similar to those currently used in advanced seismic analysis. Analytical models range from equivalent single-degree-of-freedom (SDOF) models to MDOF models. In either of these cases, numerical computation requires adequate resolution in space and time to account for the high-intensity, short-duration loading and nonlinear responses. Whenever possible, results are verified against data from tests and experiments on similar type structures and loading. Components such as beams, columns, slabs, and walls can be modelled by a SDOF system. The response can be found by the use of charts developed by Biggs [24] and military handbooks. For more complex elements, the engineer must resort to numerical time integration techniques.

\section{Performance of a Seismically Designed SDOF Model under Blast Loading}

In 2010, the Federal Emergency Management Agency (FEMA), in collaboration with the Department of Homeland Security (DHS), investigated the blast-resistant benefits of seismic design [25]. The study investigated whether structures designed for earthquakes could provide some quantifiable level of blast loading resistance. The study concluded the following:

(i) A structure's configuration, member redundancy, and shape regularity lead to an improved performance when faced with a blast.

(ii) Buildings undergoing a seismic upgrade design can benefit in terms of blast resistance performance by 

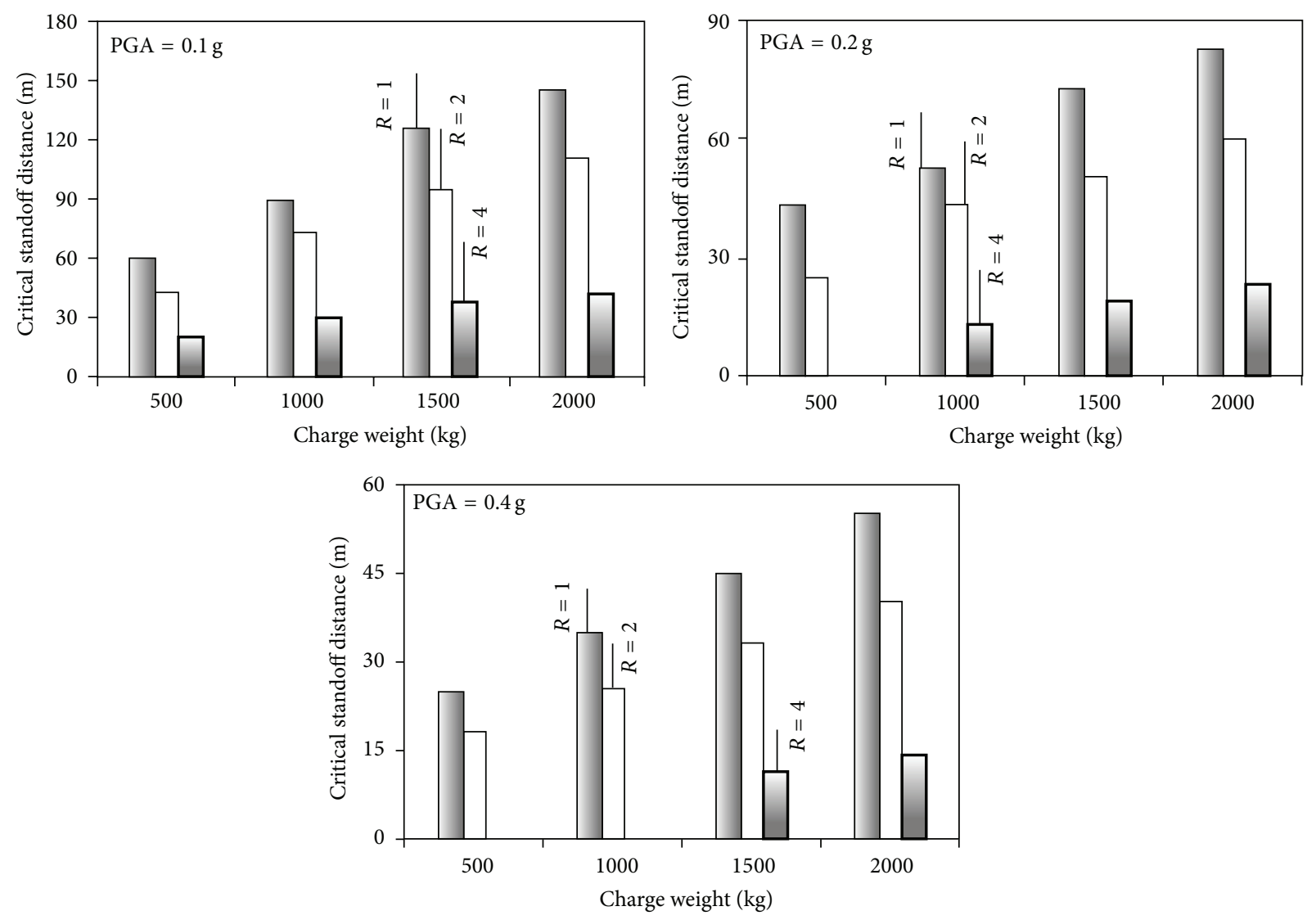

FIgURE 5: Critical distances for seismic PGAs and response ratios, $R$ [9]. Charge weight, kg of TNT.

taking into account which elements are vulnerable to blasts and upgrading those as well. However, it was found that upgrading internal structural elements does not provide any significant blast-resistant properties.

(iii) The analysis performed on the SDOF model was found to be accurate when implementing a scaled distance greater than approximately $0.7 \mathrm{~m} / \mathrm{kg}^{1 / 3}$. Also, the pressure wave (shock wave) arrived perpendicularly along the face of the structure along the building's length.

The study also continued to define the main differences between seismic forces and blast loading. A main difference is that the distribution of the energy exerted by the earthquake and the blast varies significantly. Also, earthquakes affect the entire building; however blasts loads only affect relatively small portions of the building, such as certain structural elements (columns and beams) [25].

Considering the differences between the two types of loads, earthquake resistant design is embedded into design codes and manuals throughout the world and as such provides structural benefits in terms of blast resistance as well. Earthquake design usually leads to more robust structures, hence reducing the potential of significant building damage from blasts. The peak ground acceleration (PGA) experienced by a structure is dependent on the characteristics of the earthquake and the codes implemented in the region concerned. The study investigated structures with elastic strength corresponding to PGA equivalent to $0.2 \mathrm{~g}$ and $0.4 \mathrm{~g}$ with combinations of response ratios, $R$, between 1 and 4 . The " $R$ " value corresponds to the response modification factor of the structure which indicates the ductility capability of the elements (such as the elastic or plastic ranges). It was found that as the $R$ value increases, the response decreases generally, which is a physically intuitive observation, since, essentially, $R$ indicates the ductility capacity of the system in the elastic range. Also, the response quantity was lower for larger standoff distances and higher for greater charge weights [9]. The paper summarized the critical standoff distances, beyond which the damage experienced by the structure, either by the earthquakes or by blasts, decreases so significantly that the structure can survive either elastically or inelastically.

Figure 5 depicts PGAs of $0.1 \mathrm{~g}, 0.2 \mathrm{~g}$, and $0.4 \mathrm{~g}$, which can be applied depending on the seismic zone of the experiment, and the corresponding critical standoff distances for different values of " $R$." For example, a structure located in a seismic zone designed to resist an earthquake of PGA $0.2 \mathrm{~g}$ may be able to resist blast loading of a $500 \mathrm{~kg}$ TNT charge at a standoff distance between $40 \mathrm{~m}$ for an $R$ value of 1 and $25 \mathrm{~m}$ for an $R$ value of 2 .

Kyei [26] investigated the responses of RC columns originally designed and detailed with sufficient ductility for a given magnitude of earthquake in a specific zone. The columns 


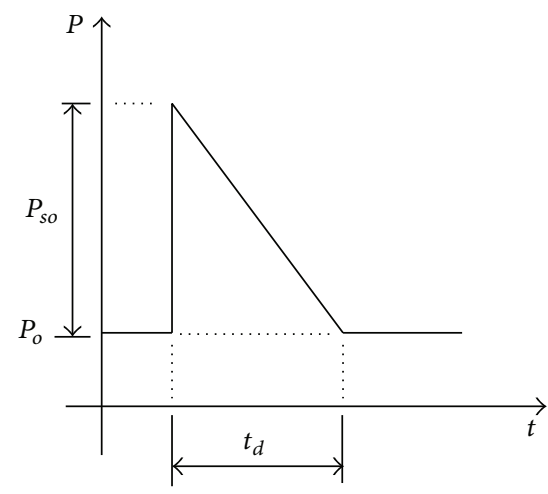

(a) Shock load

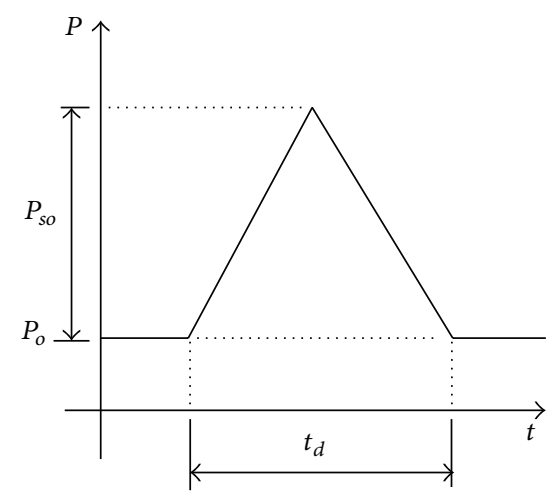

(b) Pressure load

FIgURE 6: Idealized shock and pressure loads [10].

were modelled using various seismic detailing rules as well as conventional details and a comparison of the responses was investigated. These investigations were done at various charge masses ranging between $100 \mathrm{~kg}$ and $1000 \mathrm{~kg}$ of TNT, at various scaled distances ranging between $3.71 \mathrm{~m}$ and $15 \mathrm{~m}$. For each combination of various standoff distances and charge masses, the displacement of the column increased independently of the reinforcement detailing. However, for various scaled distances $\left(0.8 \mathrm{~m} / \mathrm{kg}^{1 / 3}, 1.0 \mathrm{~m} / \mathrm{kg}^{1 / 3}\right.$, and $\left.1.5 \mathrm{~m} / \mathrm{kg}^{1 / 3}\right)$, the maximum displacement of the columns decreased significantly for the same charge masses.

The paper concluded that generally, at the same scaled distance, increasing the magnitude of the charge mass (in $\mathrm{kg}$ ) results in a greater lateral displacement and as such increases the possibility of extensive damage to the column. At higher scaled distances, the displacement response of the column decreases significantly for the same charge masses.

\section{Simplified Blast Load Function}

For the structural design of buildings, blast loading functions are simplified by idealizing the blast wave as shown in Figure 6. In order to utilize certain design formulas and charts outlined in the UFC 3-340-02 [1], a pressure wave (see Figure 2) is simplified by the use of a triangular shock wave with the same peak overpressure value and impulse loading. The negative phase is ignored.

According to Bounds [10], the pressure on the rear wall is in the opposite direction to the front wall loading and therefore reduces the lateral blast load on the overall building. In order to conservatively determine the response of the frame structure, the rear wall effects are neglected. The side walls are also excluded in the model in order to determine the maximum effects on the structure.

The front wall of the building (i.e., the wall which faces the explosion) experiences a reflected overpressure, $P_{r}$, as a result of the blast wave. It then decays to the stagnation pressure, $P_{s}$, in the clearing time $t_{c}$ (see Figure 7):

$$
\begin{aligned}
P_{r} & =\left[2+0.05 P_{s o}\right] P_{s o}(\mathrm{psi}) ; \\
& =\left[2+0.0073 P_{s o}\right] P_{s o}(\mathrm{kPa}) \\
P_{s} & =P_{s o}+C_{d} q_{o},
\end{aligned}
$$

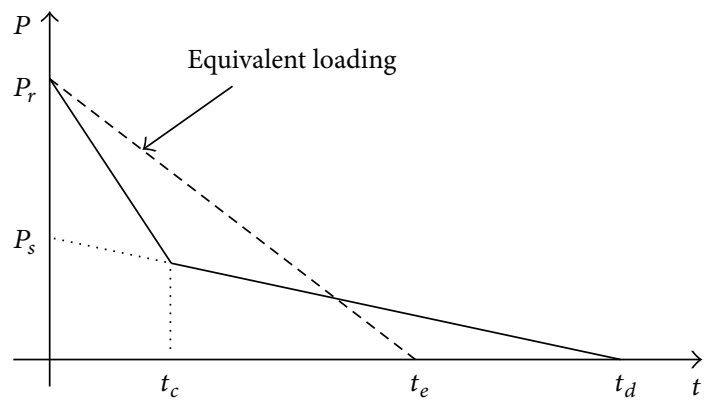

Figure 7: Front wall loading, pressure versus time [10].

where $P_{s o}$ is the peak overpressure, $q_{o}$ is the dynamic (blast wind) pressure,

$$
q_{o}=\frac{2.5 P_{s o}^{2}}{7 P_{o}+P_{s o}} \approx 0.022 P_{s o}^{2}(\mathrm{psi}) \approx 0.0032 P_{s o}^{2}(\mathrm{kPa}),
$$

and $C_{d}$ is the drag coefficient and depends on the shape and orientation of the structure. For a rectangular building, $C_{d}$ takes a value of +1.0 for front walls and -0.4 for the side walls, rear walls, and roofs. The clearing time, $t_{c}$, is defined as

$$
t_{c}=\frac{3 S}{U}<t_{d},
$$

where $t_{d}$ is the duration of the positive phase in seconds (i.e., $t_{0}$ in [27]), $U$ is the shock front velocity, and $S$ is the clearing distance in feet. Consider

$$
\begin{aligned}
U & \approx 1130\left(1+0.58 P_{s o}\right)^{0.5}(\mathrm{ft} / \mathrm{s}) \\
& \approx 345\left(1+0.0083 P_{s o}\right)^{0.5}(\mathrm{~m} / \mathrm{s}) .
\end{aligned}
$$

The clearing distance, $S$, is the smaller of $B_{H}$, or $B_{W} / 2$, where $B_{H}$ is the building height and $B_{W}$ is the building width. The bilinear pressure-time curve is shown in Figure 7. In order to utilize the dynamic response charts in UFC 3-340-02 [1], which are based on triangular shaped loads, the bilinear pressure-time curve must be simplified to an equivalent triangular load, with the same impulse. The impulse (area under the bilinear shaped load) is found using the same peak 


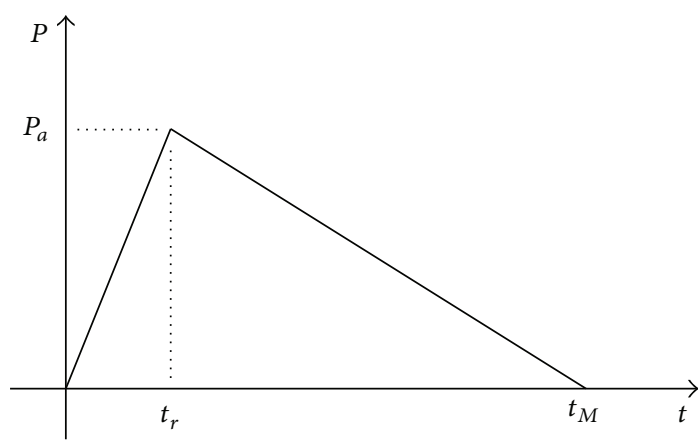

FIGURE 8: Roof loading, pressure versus time [10].

pressure $\left(P_{r}\right)$. The impulse under the bilinear pressure-time curve, $I_{w}$, is given by

$$
I_{w}=0.5\left(P_{r}-P_{s}\right) t_{c}+0.5 P_{s} t_{d} .
$$

The duration of the equivalent triangle, $t_{e}$, is now calculated as follows:

$$
t_{e}=\frac{2 I_{w}}{P_{r}}=\frac{\left(t_{d}-t_{c}\right) P_{s}}{P_{r}}+t_{c} .
$$

For a flat roof building in general (roof slope $10^{\circ}$ or less), it is normally assumed that the reflected overpressure is negligible when the blast wave travels horizontally [10]. Therefore, the predominant forces acting on the roof slab would be a combination of the side-on overpressure and the dynamic wind pressure. The dynamic wind pressure acts upward, the opposite direction of the overpressure. Also, as the wave pressure travels across the roof slab, the blast wave varies with distance and time. This results in a blast wave form as shown in Figure 8.

For the figure, $t_{r}$ is given as $B_{L} / U$, and $t_{M}$ is taken as $t_{r}+t_{d}$. The roof loading function in Figure 8 is developed by the use of the equation

$$
P_{a}=C_{e} P_{s o}+C_{d} q_{o}
$$

where $P_{a}$ is the effective side-on overpressure, $P_{s o}$ is the peak side-on overpressure, $C_{d}$ is the drag coefficient $(-0.4$, for roof slabs), $q_{o}$ is the peak dynamic pressure, and $C_{e}$ is the roof slab reduction factor which is based on Figure 9. $L_{w}$ is the length of the pressure wave which is the shock front velocity (see (5)) $\times$ duration of the positive phase, that is, $(U) \times\left(t_{d}\right) . L$ is the roof slab span between roof beams, $B_{L}$. A negative pressure by convention is pressure acting away from the surface.

\section{SDOF Analytical Model Located in Northern Trinidad}

A single-storey steel structure was designed to withstand seismic loading. The following seismic parameters were developed from the seismic hazard maps from the University of the West Indies Seismic Research Centre together with ASCE 7 [28]:

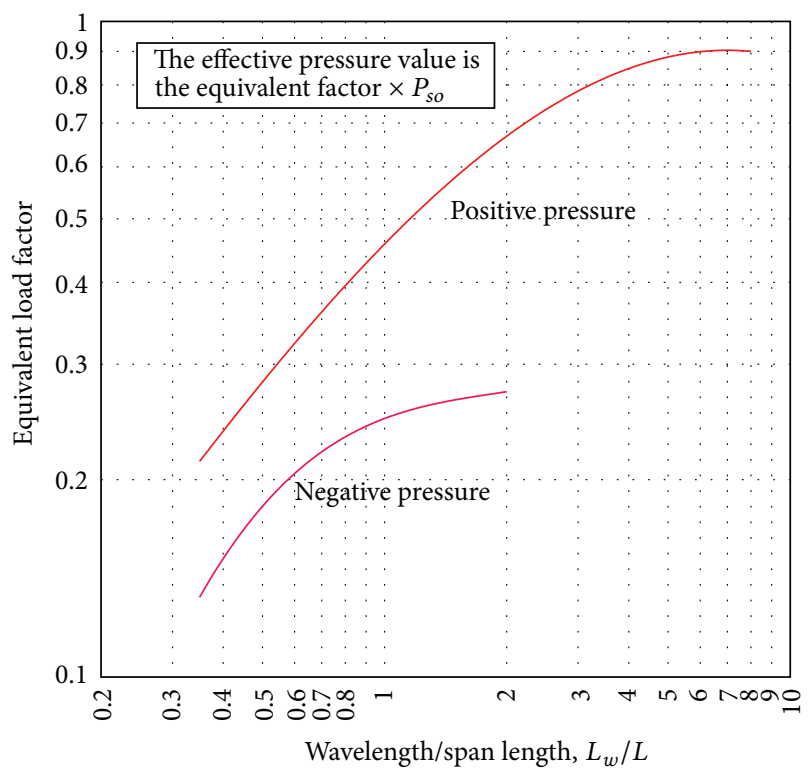

Figure 9: Peak equivalent uniform roof pressures [1].

$S_{s}$ was 1.36; $S_{1}$ was 0.35 . The site class was consistent with Northern Trinidad. The site coefficients $F_{a}$ and $F_{v}$ were defined in accordance with ASCE 7. The importance factor, $I$, was 1.25 and the occupancy category was III. The roof load used was $4.8 \mathrm{kN} / \mathrm{m}^{2}$.

For the structure used in the study, the storey drift was considered as one of the failure indicators of the building along with the plastic moment of the structural column elements. The building height was $3.3 \mathrm{~m}$, with a span of $8 \mathrm{~m}$, which was in accordance with the study by Dutta and Roy [9]. The design of the portal frame was performed using the ETABS software.

The design response spectrum (see Figure 10) was developed for an earthquake occurrence in Northern Trinidad.

The column designed was $W 14 \times 193$, and the beam size was $W 27 \times 102$. The base shear derived in the analysis was $3.6 \mathrm{kN}$. This was based on a tributary width of $8 \mathrm{~m}$. The storey drift of the frame was approximately $5 \mathrm{~mm}$. This drift response was below the maximum allowable drift of $82.5 \mathrm{~mm}$ $(0.025 \mathrm{~h})$. It was approximately 5 percent of the allowable one, indicating the structure was well within the elastic limit. Also the seismic moment for the column was $272 \mathrm{kNm}$, that is, $3 \mathrm{EI} d / h^{2}$, where EI is the flexural rigidity of the column, $h$ is the column height, and $d$ is the storey drift. This moment was less than the plastic column moment of $2049 \mathrm{kNm}$. The column again was approximately ten percent of the plastic value, indicating the column was well within the elastic zone.

The frame was also subjected to a blast load caused by applying $500 \mathrm{~kg}$ of TNT at standoff distances of $45 \mathrm{~m}, 33 \mathrm{~m}$, and $20 \mathrm{~m}$ and its responses were investigated.

Due to both the length of the building and the standoff distance, the overpressure and its duration were considered to have negligible variation over the length of the building. The scaled distance, $Z$ [27], was given by

$$
Z=\frac{(\text { standoff distance }(\mathrm{ft}))}{(\text { blast weight }(\mathrm{lbs}))^{1 / 3}} .
$$


TABLE 2: Standoff distances and blast response.

\begin{tabular}{lcc}
\hline Standoff distance, $\mathrm{m}$ & $\begin{array}{c}\text { Peak horizontal } \\
\text { response, mm }\end{array}$ & $\begin{array}{c}\text { Peak vertical } \\
\text { response, } \\
\text { mm }\end{array}$ \\
\hline 45 & 0.46 & 40.6 \\
33 & 0.82 & 68.5 \\
20 & 1.9 & $340.3^{*}$ \\
\hline
\end{tabular}

${ }^{*}$ Approximate nonlinear analysis.

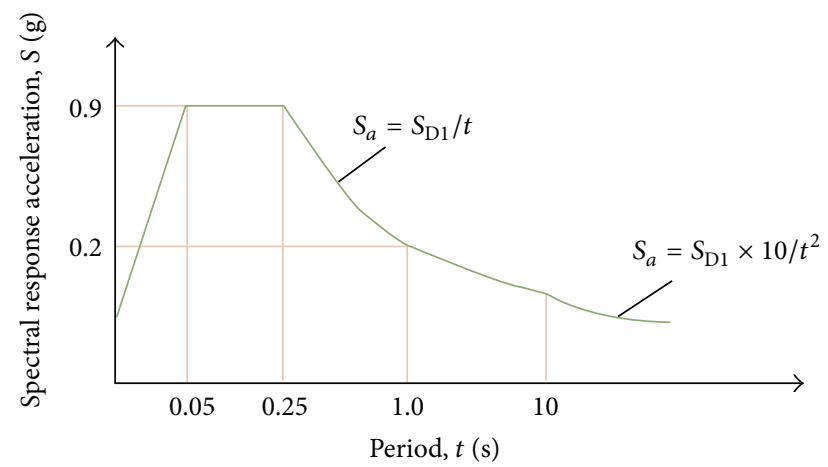

FIGURE 10: Design response spectrum based on the IBC.

For the standoff distance of $45 \mathrm{~m}$, after conversion, the scaled distance was 14.3; and, from the log plot (Dusenberry, ibid.), the overpressure, $p_{s o}$, was $5.3 \mathrm{psi}(36.5 \mathrm{kPa})$. Using the same plot, $t_{d}$ which was given as $t_{0}$ was $31 \mathrm{msec}$, or $0.031 \mathrm{~s}$. The reflected overpressure clearing time, $t_{c}$ given by (4), was $0.025 \mathrm{~s}$, which was less than $t_{d}$, and was therefore acceptable. The drag coefficient, $C_{d}$, was 1 , and the stagnation pressure, $p_{s}$ (see (2)), was $5.92 \mathrm{psi}(40.8 \mathrm{kPa})$. The front wall impulse, using (6), was $0.168 \mathrm{psi}-\mathrm{s}(1.2 \mathrm{kPa}-\mathrm{s})$. The effective duration, $t_{e}$ (see (7)), was $0.028 \mathrm{~s}$, and $p_{r}$, the reflected overpressure, was $12 \mathrm{psi}$ (see (1)). The resulting function was plotted in Figure 11. For the roof member, the roof was taken as spanning $1 / 3$ of the full tributary width, that is, $2.66 \mathrm{~m}(8.73 \mathrm{ft})$. The rise time, $t_{r}$, was then $B_{L} / U(8.73 / 1292.06)$, that is, $0.0068 \mathrm{sec}$, and $p_{a}$ (see (8)) was 4.64 psi. The time duration, $t_{M}$, was $0.038 \mathrm{~s}$. The resulting plot of the blast function for the roof is shown in Figure 12. The resulting blast load functions for standoff distances of $33 \mathrm{~m}$ and $20 \mathrm{~m}$ are shown in Figure 13.

The resulting peak displacement values for the various standoff distances are shown in Table 2. The critical damping for the model used was 5 percent.

The entire response functions are shown in Figures 1418. The responses for the drift or horizontal response were given with respect to the top of the column, and the vertical response was given with reference to the mid-span node of the first floor beam. These were deemed to be the critical points. This paper focused on the transient phase of the response since the forcing functions were basically impulse loads, and the steady state response dies off quickly.

\section{Discussion}

For the structure analysed in this study, the maximum response occurs almost instantaneously, with the suction

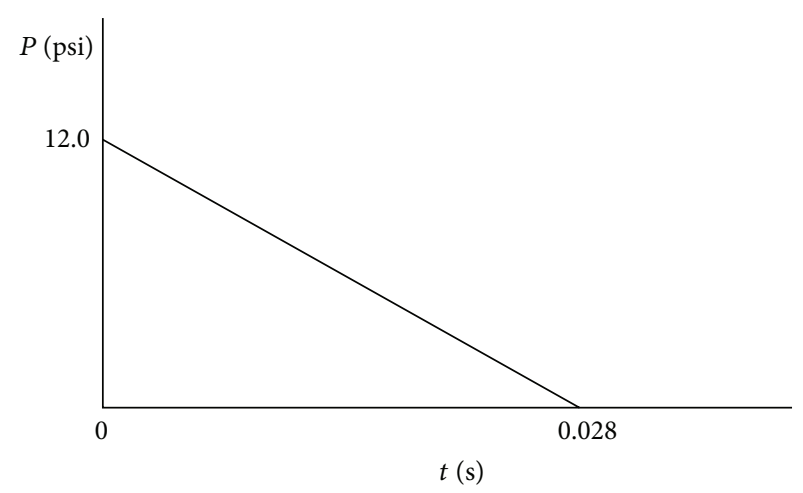

Figure 11: Blast load function on the front wall for $500 \mathrm{~kg}$ TNT, for standoff distance $45 \mathrm{~m}$.

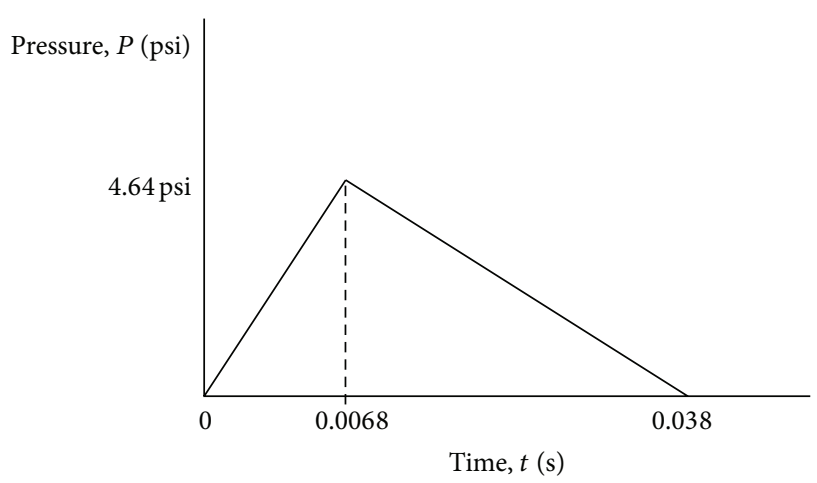

Figure 12: Blast load function on the roof for $500 \mathrm{~kg}$ TNT, for standoff distance $45 \mathrm{~m}$.

effect discussed earlier, being more pronounced for the larger standoff distances. At the minimum standoff distance of $20 \mathrm{~m}$, the drift or lateral response of the frame was in the elastic range; that is, $d$ was less than $82 \mathrm{~mm}$. For the vertical response, in most design codes, the allowable deflection is usually of the order $L / 240$, or $33.3 \mathrm{~mm}$. Although this is a live load requirement, it gives an idea of the order of magnitude required. For the plastic limit distributed load, $w_{p}$, of $16 M_{p} / L^{2}$, that is, $437 \mathrm{kN} / \mathrm{m}\left(M_{p}\right.$ is the plastic moment and $L$ is the beam span), the plastic limit deflection was $77 \mathrm{~mm}$, that is, $w_{p} L^{4} / 384$ EI. This is the limiting deflection just before the structure yields. This indicates that at standoff distances of $45 \mathrm{~m}$ and $33 \mathrm{~m}$ the structure remained elastic.

Using an approximate nonlinear analysis, with a hinge located at mid-span of the first floor beam, the deflection was $340.3 \mathrm{~mm}$ (13.4 in) at $0.061 \mathrm{~s}$, indicating the beam was clearly in the plastic zone since this load case produced a deflection also greater than $77 \mathrm{~mm}$. The following limitations should be noted regarding the nonlinear analysis:

(i) Very large displacements, instability of the structure, and/or postbuckling behavior was not considered.

(ii) Geometric nonlinearity was considered. No tension/compression or contact was considered. Bilinear behavior was not considered. 

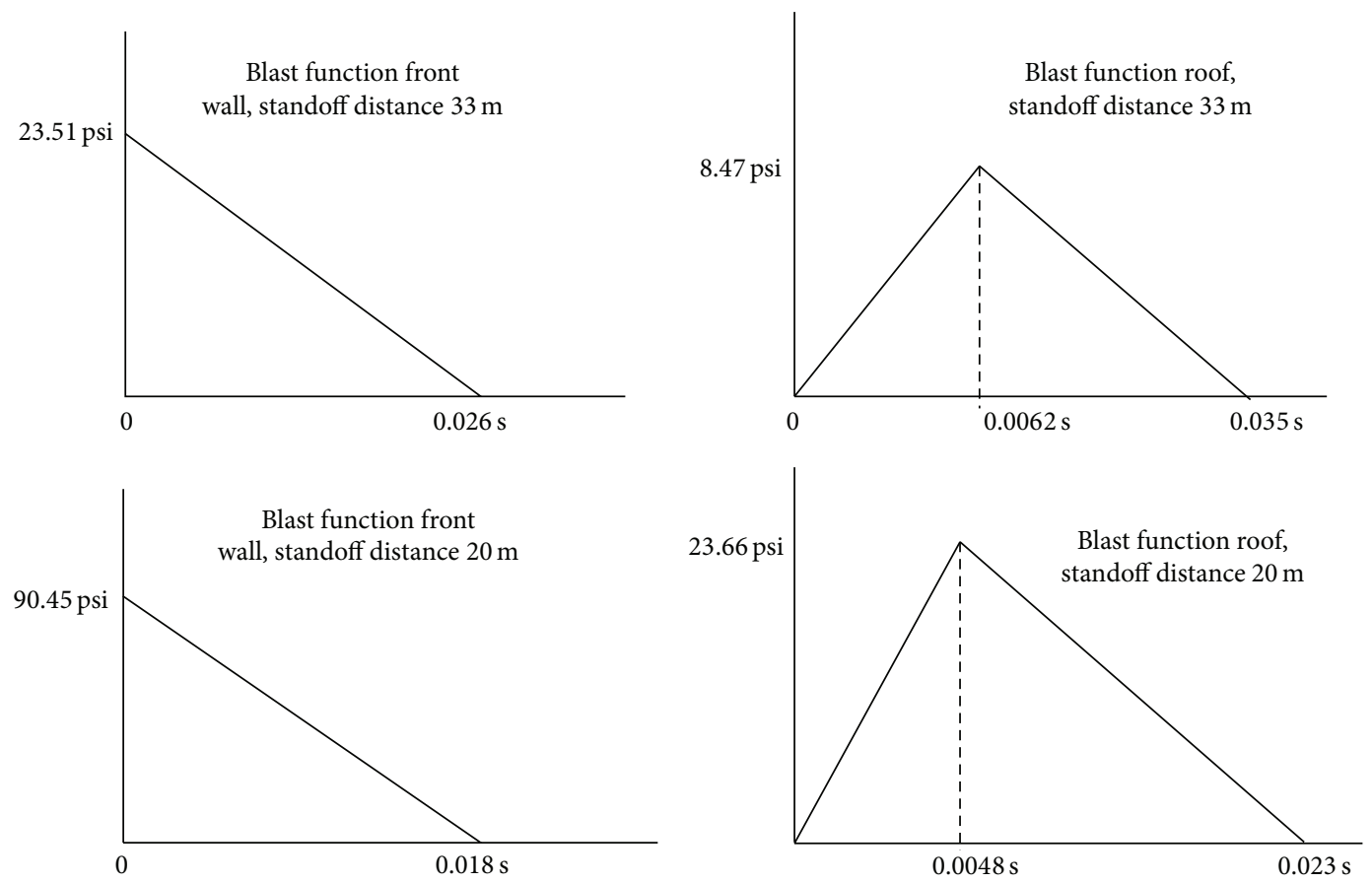

FIGURE 13: Blast load functions for standoff distances $33 \mathrm{~m}$ and $20 \mathrm{~m}$.

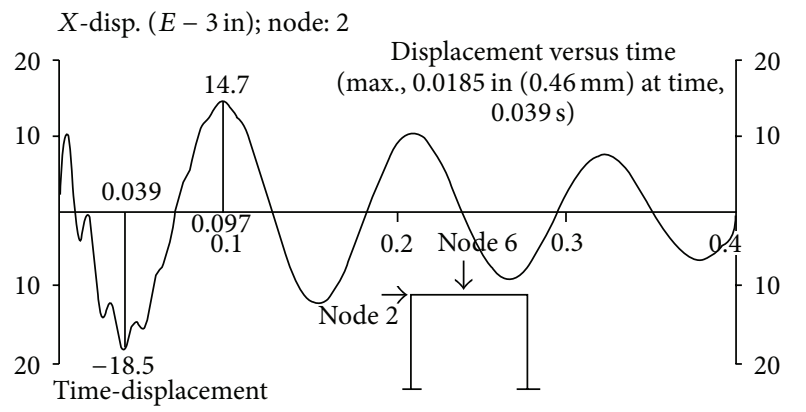

FIGURE 14: Horizontal response function for standoff distance $45 \mathrm{~m}$.

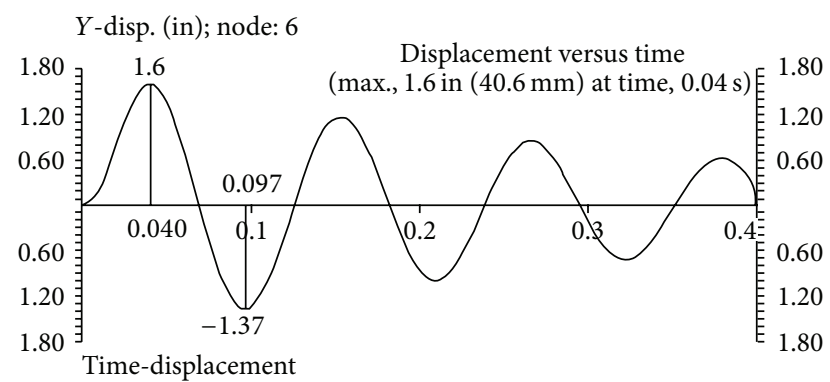

FIGURE 15: Vertical response function for standoff distance $45 \mathrm{~m}$.

It is assumed that, for this study, the likelihood of the occurrence of a prearranged blast (such as terrorist activity) is relatively low and as such the model would be allowed to undergo a high damage level. In other words, the risk is low, and the user would perhaps require that the building be designed to incur some level of damage in order to reduce

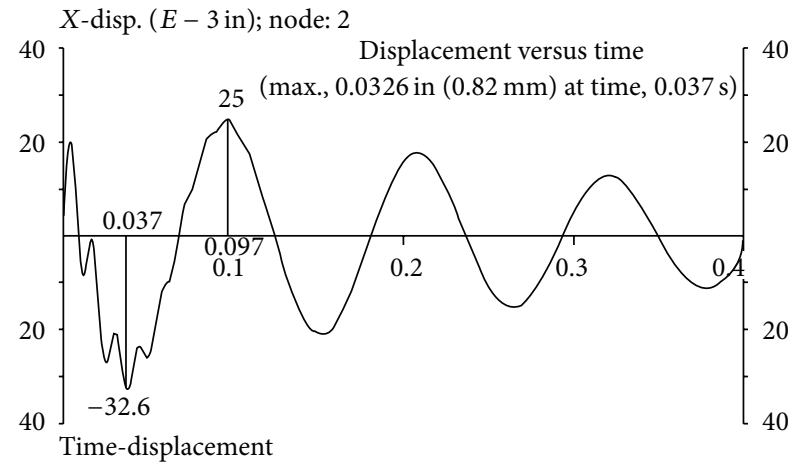

FIGURE 16: Horizontal response function for standoff distance $33 \mathrm{~m}$.

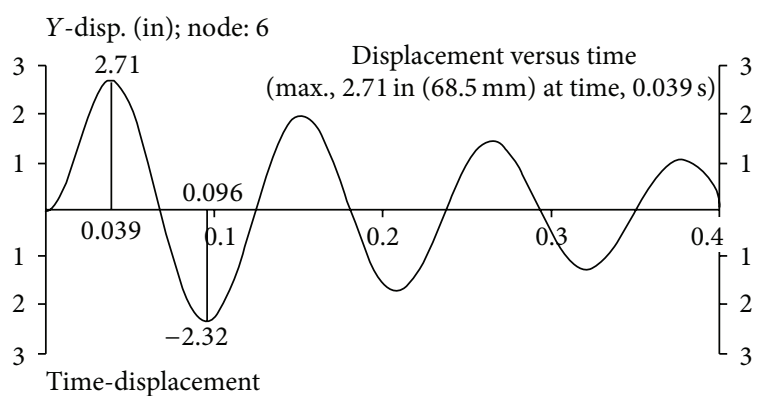

FIGURE 17: Vertical response function for standoff distance $33 \mathrm{~m}$.

the overall building cost, consistent with a performance based approach. In determining the appropriate response for any structure, careful risk assessments which would evaluate the accident probability, as well as terrorist activity, 


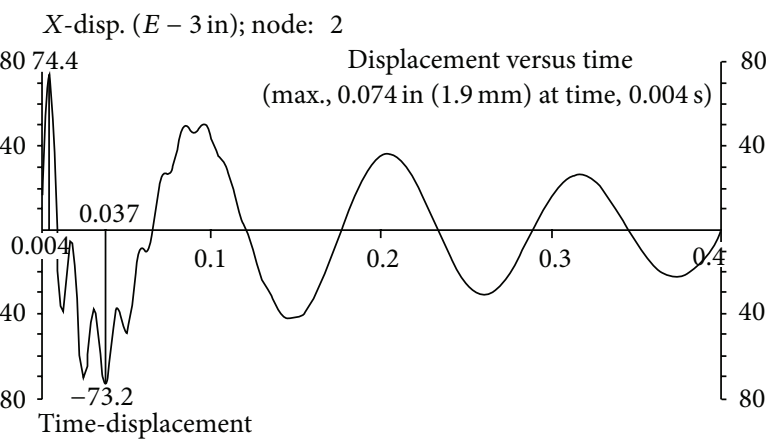

FIGURE 18: Horizontal response function for standoff distance $20 \mathrm{~m}$.

would assist in determining the most appropriate degree of response.

With the IBC, depending on the structure, it is compulsory to carry out P-delta analyses, or direct analysis procedures [29]. And from the results of this paper, these procedures would further ensure the columns remain in the elastic range for moderate earthquakes and by extension blast loads at the standoff distances studied, although beam failure may still be a problem. The SDOF numerical analysis is limited since most structures, although of a single storey in nature, may have several degrees of freedom when we consider the torsional rotation of the roof slab. The SDOF equivalent analysis approach allows the strain energy of the structural members to be balanced by the kinetic energy of the explosion and therefore allows the energy to be absorbed by said members. The strain energy of the members is dependent on the amount of permitted deformation of the member, as well as the section and material properties of the members, while the energy required to be absorbed by the member as a result of the blast duration and peak functions is as described in the paper.

The method put forward in this paper is useful at the preliminary design stage, as results are sufficiently accurate according to the blast-resistant design procedures currently in use. Damage of buildings due to external wall damage, that is, glass facades, and so forth was not considered in this study.

\section{Conclusions}

Although design guidelines exist for the design of structures subjected to blast loads, they are rarely implemented in building design for conventional structures. It is, however, a requirement that buildings be designed to incorporate a level of seismic protection, depending on the seismic zone of the structure. This paper compared the performances of a seismically designed SDOF frame structure at blast loads at various standoff distances. For the charge weight used in this study, the main beam entered the plastic zone at the critical standoff distance. This indicates that once seismic codes are followed and a building is detailed accordingly, the probability of withstanding a blast load of the magnitude studied is uncertain and should be further investigated. This study is purely comparative since the positive effect for the design due to earthquakes and the behavior of the frame is different from the behavior of the frame under blast loading. Although the SDOF numerical model is a simplified model, it gives conservative results based on drift criteria. The SDOF model is more appropriately suited for preliminary design of structures since there are more approximations and assumptions; however it can be performed quickly and efficiently. A MDOF numerical model should be used when detailed design is necessary in order to accommodate a more economical design.

\section{Competing Interests}

The authors declare that they have no competing interests.

\section{References}

[1] UFC, "Structures to resist the effects of accidental explosions," UFC 3-340-02, Unified Facilities Criteria, Department of Defense, Washington, DC, USA, 2014.

[2] T. P. Tadepalli, Performance Evaluation of Low-Rise Concrete Frame Building Structures in Moderate Seismic Zones Subject to External Blast Loading, University of Mississippi, University, Miss, USA, 2010.

[3] L. K. Stewart, Testing and analysis of structural steel columns subjected to blast loads [Ph.D. thesis], University of California, San Diego, San Diego, Calif, USA, 2010.

[4] J. Godinho, A. Montalva, and S. Gallant, "Analysis of steel columns for air-blast loads," Structure Magazine, pp. 13-14, 2007.

[5] P. D. Smith and J. G. Hetherington, Blast and Ballistic Loading of Structures, Butterworth-Heinemann, Oxford, UK, 1994.

[6] I. Javed, Effects of an external explosion on a concrete structure [Ph.D. thesis], University of Engineering and Technology, Taxila, Pakistan, 2009.

[7] T. Ngo, P. Mendis, A. Gupta, and J. Ramsay, "Blast loading and blast effects on structures-an overview," Electronic Journal of Structural Engineering, vol. 7, pp. 76-91, 2007.

[8] W. P. M. Marx, "The consequences of explosion effects on structures, committee for the prevention of disasters caused by dangerous substances," in Methods for the Determination of Possible Damage to People and Objects Resulting from Releases of Hazardous Materials (Green Book CPR 16E), p. 13, DirectorateGeneral of Labour of the Ministry of Social Affairs and Employment III, The Hague, Netherlands, 1992.

[9] S. C. Dutta and R. Roy, "Performance of seismically designed buildings under blast loading," Iranian Journal of Science and Technology - Transactions of Civil Engineering, vol. 36, no. 2, pp. 149-166, 2012.

[10] W. L. Bounds, Design of Blast-Resistant Buildings in Petrochemical Facilities, American Society of Civil Engineers, Reston, Va, USA, 2nd edition, 2010.

[11] V. Karlos and G. Solomos, "Calculation of blast loads for application to structural components: administrative arrangement no JRC 32253-2011 with DG-HOME activity A5-blast simulation technology development," Tech. Rep., Joint Research Centre (JRC), European Union, Luxembourg City, Luxembourg, 2013.

[12] G. Mays, P. Smith, and D. Cormie, Blast Effects on Buildings, Institution of Civil Engineers (ICE), London, UK, 2nd edition, 2009. 
[13] W. E. Baker, P. S. Westine, and F. T. Dodge, Similarity Methods in Engineering Dynamics: Theory and Practice of Scale Modeling, Elsevier Science, Amsterdam, The Netherlands, 1991.

[14] A. Longinow and F. Alfawakhiri, "Blast resistant design with structural steel," Modern Steel Construction, vol. 43, no. 10, pp. 61-66, 2003.

[15] A. M. Remennikov, "A review of methods for predicting bomb blast effects on buildings," Journal of Battlefield Technology, vol. 6, no. 3, pp. 5-10, 2003.

[16] A. T. Hussein, "Non-linear analysis of SDOF system under blast load," European Journal of Scientific Research, vol. 45, no. 3, pp. 430-437, 2010.

[17] P. Esper, "Performance of buildings under blast loading and recommended protective measures," in Proceedings of the International Symposium on Network and Center-Based Research for Smart Structures Technologies and Earthquake Engineering (SE '04), Osaka, Japan, July 2004.

[18] J. Li, C. Wu, and H. Hao, "An experimental and numerical study of reinforced ultra-high performance concrete slabs under blast loads," Materials and Design, vol. 82, pp. 64-76, 2015.

[19] J. Xu, C. Wu, H. Xiang et al., "Behaviour of ultra high performance fibre reinforced concrete columns subjected to blast loading," Engineering Structures, vol. 118, pp. 97-107, 2016.

[20] F. Parisi, C. Balestrieri, and D. Asprone, "Blast resistance of tuff stone masonry walls," Engineering Structures, vol. 113, pp. 233244, 2016.

[21] A. Goyal, "Blast resistant design: critical issues," in Proceedings of the 6th Structural Engineering Convection, pp. 1-10, Structural Engineering Research Centre (SRC), Chennaai, India, December 2008 .

[22] N. N. Moon, Prediction of blast loading and its impact on buildings [Master of Technology Thesis], National Institute of Technology, Rourkela, India, 2009.

[23] Federal Emergency Management Agency, Risk Assessment: A How-To Guide to Mitigate Potential Terrorist Attacks Against Buildings, FEMA 452, Federal Emergency Management Agency, Department of Homeland Security, Washington, DC, USA, 2005.

[24] J. M. Biggs, Introduction to Structural Dynamics, McGraw-Hill Book, New York, NY, USA, 2nd edition, 1964.

[25] FEMA P-439B, Blast-Resistant Benefits of Seismic Design, Phase 2 Study: Performance Analysis of Structural Steel Strengthening Systems, Federal Emergency Management Authority, Department of Homeland Security, Washington, DC, USA, 2010.

[26] C. Kyei, Effects of bast loading on seismically detailed reinforced concrete columns [Master of Applied Science Thesis], Carleton University, Ottawa, Canada, 2014.

[27] D. O. Dusenberry, Handbook for Blast Resistant Design of Buildings, John Wiley \& Sons, New York, NY, USA, 2010.

[28] American Society of Civil Engineers, Minimum Design Loads for Buildings and Other Structures, ASCE/SEI 7-10, American Society of Civil Engineers, Reston, Va, USA, 2010.

[29] IBC, International Building Code, International Code Council, Inc., USA, 2012. 


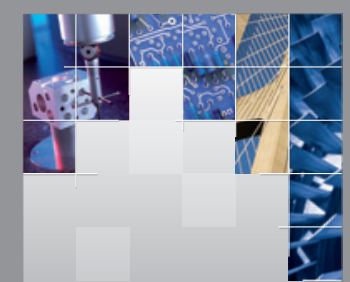

\section{Enfincering}
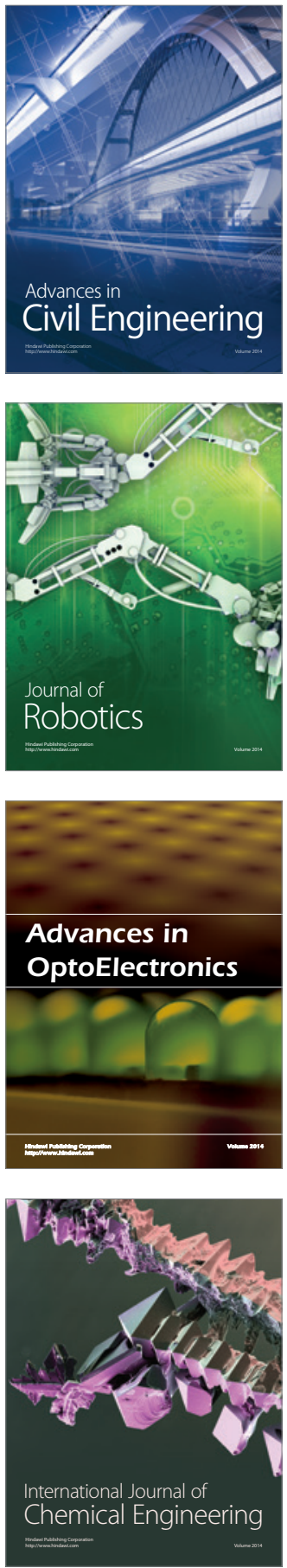

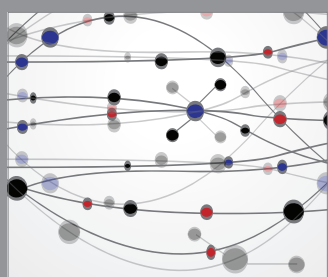

The Scientific World Journal

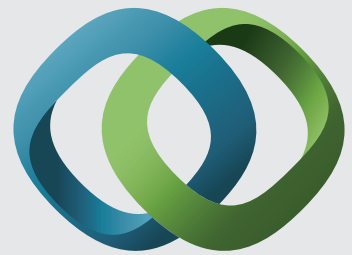

\section{Hindawi}

Submit your manuscripts at

http://www.hindawi.com
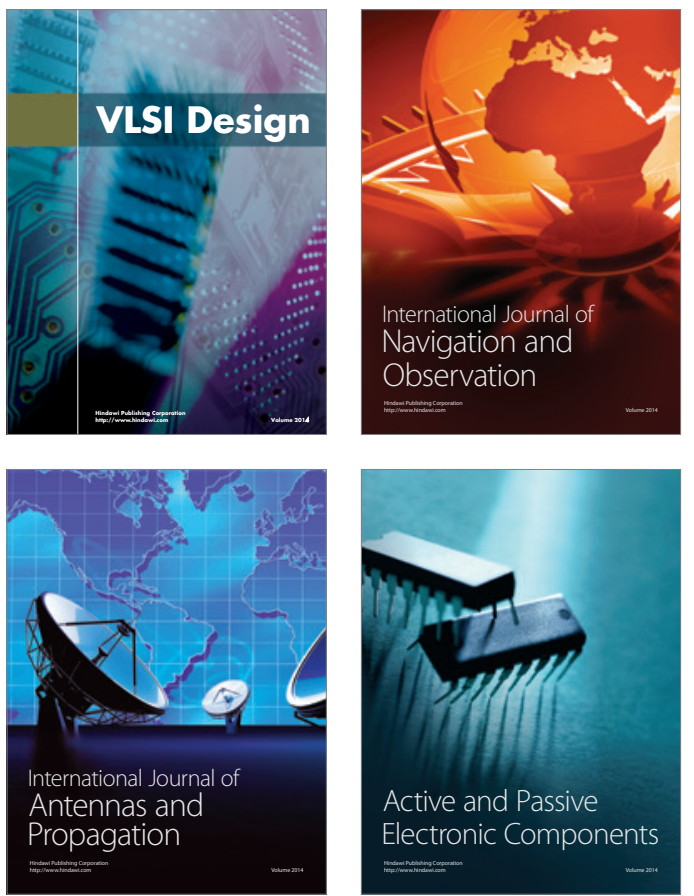
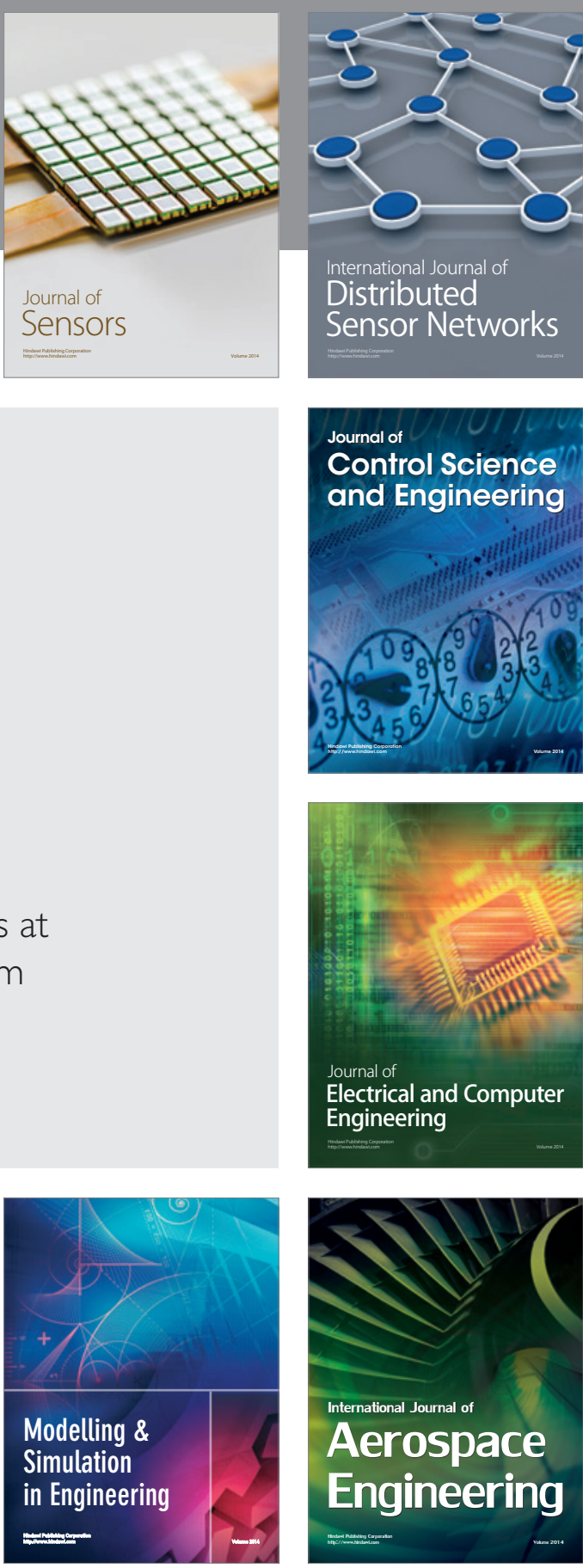

International Journal of

Distributed

Sensor Networks

Journal of

Control Science

and Engineering
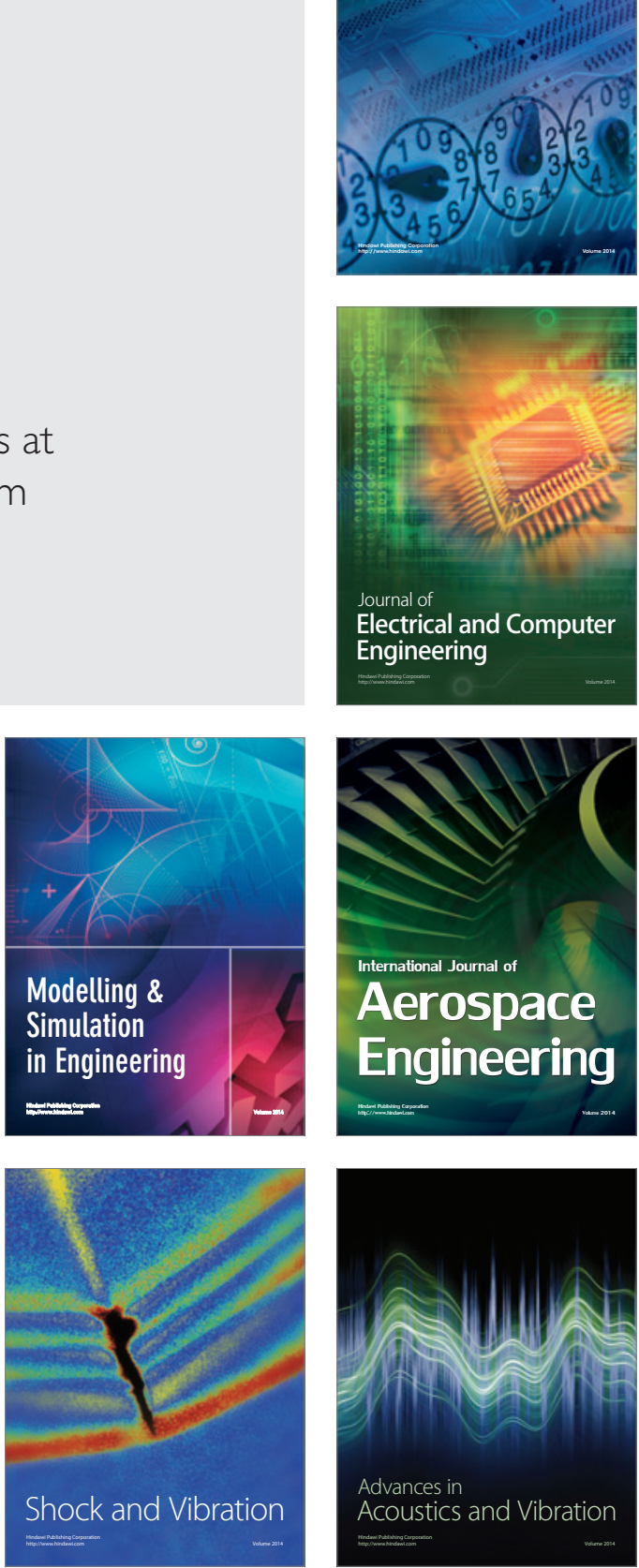